\section{LETTERS}

\section{Cutaneous \\ leucocytoclastic vasculitis caused by cyclosporin A (Sandimmun)}

Cutaneous leucocytoclastic vasculitis to cyclosporin A (Sandimmun) has not been previously described. We report the case of a 37 year old man who presented with a 10 day history of a purpuric eruption affecting both legs. He had been diagnosed as having psoriasis and psoriatic arthropathy 12 years previously, on the basis of joint symptoms, sacroileitis, erosive arthropathy, increased acute phase reactants and positive HLA B27 status. His initial treatments had included oral gold (Auranofin) $3 \mathrm{mg}$ three times per day and salazopyrine $3 \mathrm{~g}$ /day. Both were discontinued because of poor control of his joint disease. In July 1997 he was given ora cyclosporin A (Neoral) $50 \mathrm{mg} /$ day, which was increased to $100 \mathrm{mg} /$ day. This was discontinued in January 1998 because of symptoms of fatigue. In April 1998, after further flares of his arthropathy, he was given Sandimmun 50 $\mathrm{mg} /$ day by his general practitioner. Within one month of this he developed an acute skin eruption. He was otherwise well and receiving no other medication except indomethacin $150 \mathrm{mg} /$ day, which he had been taking since 1986.

On examination, there was a palpable, non-tender, purpuric eruption with necrotising ulceration localised to both lower legs. Routine haematology, biochemistry and urine analysis were normal. Skin biopsy showed a leucocytoclastic vasculitis with heavy dermal neutrophilic infiltrate and few eosinophils (fig 1). Gram stain for organisms was negative.

The Sandimmun was discontinued and over a two month period, the purpuric eruption and ulcers healed with residual scarring.

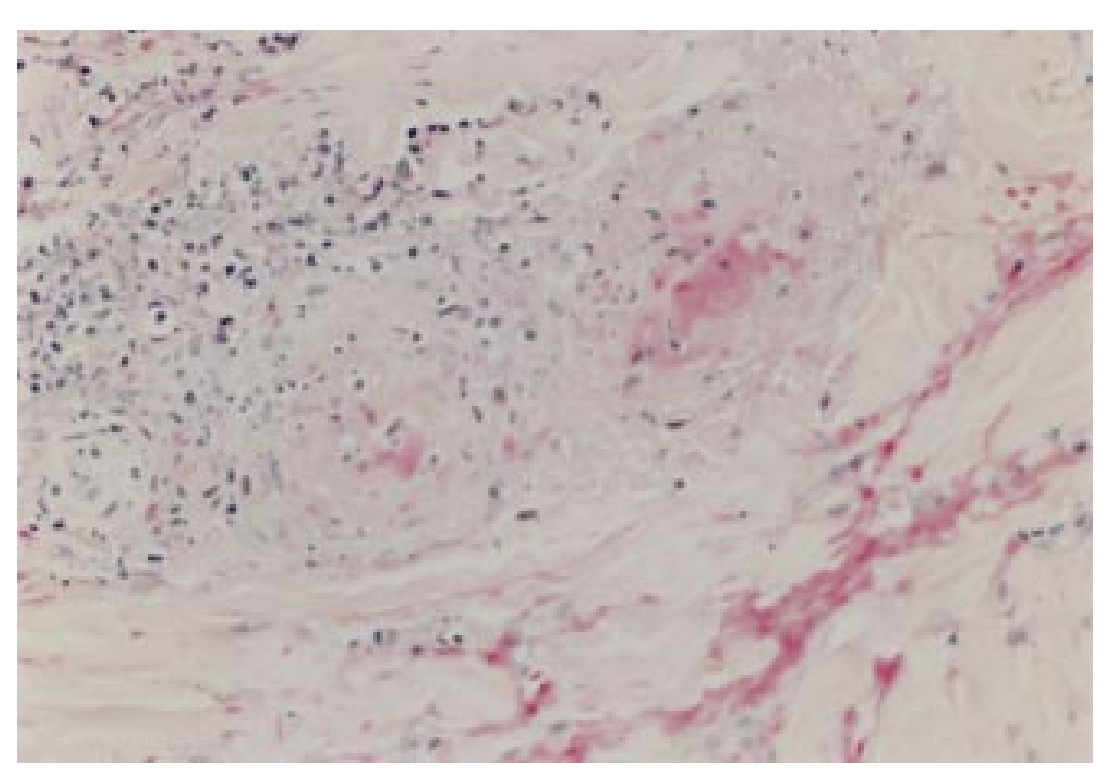

Figure 1 Histological examination showing endothelial cell swelling, thrombosed dermal vessels, dermal neutrophilic infiltrate with scanty eosinophils, nuclear dust and red cell extravasation consistent with leucocytoclastic vasculitis (haematoxylin and eosin stain $\times 250$ ).
At nine month follow up, the patient was not taking cyclosporin A with no recurrence of his vasculitis.

Leucocytoclastic vasculitis may be secondAlthough numerous cutaneous eruptions have been reported with Sandimmun, ${ }^{2}$ there is only one report of it causing a vasculitictype of rash. ${ }^{3}$ This report reviewed the cutaneous findings in 67 patients treated with cyclosporin A. Three patients $(4.4 \%)$ were found to have Bateman's or senile purpura, ${ }^{4}$ although skin biopsies were not performed. Our patient developed a cutaneous leucocytoclastic vasculitis to Sandimmun but not to Neoral. Apart from the active drug, Sandimmun has corn oil and polyoxyethylated glycolysed glycerides as the base, while Neoral has corn oil and a polyoxyl 40 hydrogenated castor oil.

It is possible that the leucocytoclastic vasculitis seen in our patient occurred by chance. However, as a reaction to the base of Neoral has been reported previously ${ }^{5}$ and because of the temporal relation between the use of the drug and the onset of the skin eruption, we postulate that the vasculitis was more likely to be attributable to the constituents of the base of Sandimmun rather than the active drug

M N GUPTA R D STURROCK Centre for Rheumatic Diseases, University Department of Medicine, Glasgow Royal Infirmary, Glasgow

G GUPTA

Department of Dermatology, Glasgow Royal

Correspondence to: Dr G Gupta, Department of Dermatology, Monklands Hospital, Monklands Avenue, Airdrie, Lanarkshire ML6 0JS

1 Lotti T, Ghersetich I, Comacchi C, Jorizzo JL. Cutaneous small-vessel vasculitis. J Am Acad Dermatol 1998;39:667-87.

2 Litt JZ, Pawlak WA Jr, eds. Drug eruption reference manual. New York: The Parthenon Publishing Group, 1997:126-8.

3 Bencini PL, Montagnino G, Sala F, De Vecchi A, Crosti C, Tarantino A. Cutaneous lesions in 67 cyclosporin-treated renal transplant recipients. Dermatologica 1986;172:24-30. ary to a variety of drugs or infections. ${ }^{1}$

4 Dowd PM, Champion RH. Purpura. In: Champion RH, Burton JL, Burns DA, Breathnach pion RH, Burton JL, Burns DA, Breathnach SM, eds. Textbook of dermatology. Oxford: Blackwell Scientific Publications, 1998:2146. 5 Volcheck GW, Van Dellen RG. Anaphylaxis to intravenous cyclosporine and tolerance to oral cyclosporine: case report and review. Ann Allergy Asthma Immunol 1998;80:159-63.

\title{
An evidence based EULAR meeting?
}

One of the main themes of the very successful EULAR Meeting in Glasgow was "Evidence Based Rheumatology". Also prominent at the meeting were pharmaceutical companies promoting COX 2 inhibitors. Much of this promotional activity, some of which was supported by academic speakers, was for the use of these agents in osteoarthritis. However, the evidence base does not support the use of anti-inflammatory agents in osteoarthritis $^{12}$ and current guidelines on the management of this disease suggest the use of simple analgesics rather than non-steroidal anti-inflammatory drugs (NSAIDs). ${ }^{3}$ Some years ago, we showed that publications on NSAIDs were dominated by comparative studies of different NSAIDs, rather than more necessary studies, such as comparisons between NSAIDs and simple analgesics ${ }^{4}$; sadly, the appearance of a new class of NSAIDs does not seem to have led to any change in the type of trial being sponsored by the industry. How can we justify holding a large international meeting with an evidence based theme, while including a large amount of information that runs counter to the available evidence?

PAUL DIEPPE

MRC Health Services Research Collaboration, University of Bristol, Cannynge Hall, Whiteladies Road, Bristol BS8 2PR

1 Towheed T Hochberg M. RCTs of pharmacological therapy in osteoarthritis of the knee: a systematic review. Arthritis Rheum 1996;39 (suppl 9):1184.

2 Towheed T, Shea B, Wells G, Hochberg M. Osteoarthritis: a systematic review of randomised controlled trials of analgesia and antiinflammatory therapy in osteoarthritis of the hip. Cochrane Review Group, 1997. Cochrane Library Issue 1 1999, Search date 1994.

3 Hochberg M, Altman R, Brandt K, Clark BM, Dieppe PA, Griffin MR, et al. Guidelines for the medical management of osteoarthritis. Arthritis Rheum 1995; 38:1535-46.

4 Dieppe P, Toth B, Frankel S. Is research into the treatment of osteoarthritis with non-steroidal anti-inflammatory drugs misdirected? Lancet 1993;341:353-4.

MATTERS ARISING

\section{Psychosocial risks for low back pain: are these related to work?}

In an interesting prospective study, Papageorgiou et al, ${ }^{1}$ reported that in a low back pain free population dissatisfaction with work status doubled the risk of reporting a new low back pain episode in the employed and non-employed. This is an interesting finding that adds to the literature on the importance of worker job perceptions to 
the development of low back pain episodes. In this report, however, Papageorgiou et $a l^{1}$ neglected to discuss previous research on the importance of pre-injury job perceptions to chronic low back pain patients' intent to return to work after treatment.

In a series of four papers, Fishbain and colleagues have attempted to determine if pre-injury job satisfaction impacts on "intent" to return to work to the pre-injury job after pain facility treatment. In the first report Fishbain et $a l^{2}$ demonstrated that chronic pain patients not intending to return to work after pain facility treatment were more likely to complain of job dissatisfaction. In the second report from this group, Rosomoff et $a l^{3}$ demonstrated that an association between non-intent to return to work after pain facility treatment and pre-injury job dissatisfaction was similarly found across Workers' Compensation and non-Workers Compensation chronic pain patients. In the third report, Fishbain et $a l^{4}$ looked at actua return to work after pain facility treatment in relation to these variables. They found that actual return to work was predicted at one month "by intent", perceived job stress and job like (job dissatisfaction) plus other variables. At 36 months, return to work was predicted by "intent" and by perceived job stress plus other variables. In the final study, Fishbain $e t a \bar{l}$ attempted to predict "intent" to return after pain facility treatment in relation to actual return to work. "Intent" was predicted by perceived pre-injury job stress plus other variables. In addition, those chronic pain patients who intended to return and did not were predicted by whether there was a job to go back to. Also chronic pain patients not intending to go back to work at the pre-injury job, but doing so, were predicted by having a job to go back. Overall, this series of studies points to a strong relation between pre-injury work variables such as job dissatisfaction and "intent" to return to that job after treatment. In addition, these studies indirectly support the findings of Papageorgiou et al. ${ }^{1}$ It seems that in trying to understand the low back pain injury and recovery process, it is important to take into account work related perceptions such as those of perceived job dissatisfaction and job stress.

DAVID A FISHBAIN

University of Miami School of Medicine, University of Miami Comprehensive Pain and Rehabilitation Center, USA

1 Papageorgiou AC, Croft Pr, Thomas E, Silman AJ, Macfarlane GJ. Psychosocial risks for low
back pain: are these related to work? Ann back pain: are these related
Rheum Dis 1998;57:500-2.

2 Fishbain DA, Rosomoff HL, Cutler R, Steele Rosomoff R. Do chronic pain patients' perceptions about their preinjury jobs determine their intent to return to the same type of job post-pain facility treatment? Clin J Pain 1995; 11:267-78

3 Rosomoff HL, Fishbain, DA, Cutler R, Steele Rosomoff R. Do chronic pain patients' perceptions about their preinjury jobs differ as a function of worker compensation and non-worker compensation status? Clin J Pain 1995;11:279-86.

4 Fishbain DA, Cutler R, Rosomoff HL, Khalil T, Steele Rosomoff R. Impact of chronic pain patients' job perception variables on actual

5 Fishbain DA Cutler R Rosomoff HL Khali1 T, Steele Rosomef R. Rosomofiction Steele Rosom "intent", and "discrepanc pain patient "intent", and "discrepancy with non-intent" for return to work post pain facility 